\title{
Optimal Testing for Diagnosis of Fructose Intolerance: Over-dosage Leads to False Positive Intolerance Test
}

TO THE EDITOR: We read with interest the recent article by Goebel-Stengel et $\mathrm{al}^{1}$ and wish to express our appreciation and enthusiasm for their work on small intestinal bacterial overgrowth (SIBO) and carbohydrate intolerance in patients with irritable bowel syndrome (IBS). However, we have significant concerns regarding their methodology and basis for diagnosis of fructose intolerance.

Goebel-Stengel et $\mathrm{al}^{1}$ used a supra-physiologic dose of $50 \mathrm{~g}$ fructose in $200 \mathrm{~mL}$ water for performing the fructose breath test. The rationale for this high dose is unclear, and whether healthy controls from their population can fully absorb $50 \mathrm{~g}$ dose of fructose has not been reported by these authors. If the test was positive, an additional breath test was performed with $25 \mathrm{~g}$ in 100 $\mathrm{mL}$ water. Patients were then classified as subjects with moderate symptomatic fructose malabsorption if they were positive with 50 $\mathrm{g}$ dose and negative with $25 \mathrm{~g}$ dose, and severe fructose malabsorbers as patients who were positive at both doses. Since almost all healthy subjects can absorb up to $25 \mathrm{~g}$ of fructose, and $70 \%$ malabsorb at $50 \mathrm{~g}$ dose, ${ }^{2}$ it is unclear why the authors chose a $50 \mathrm{~g}$ fructose dose. Authors have partially justified this dose stating that daily consumption of fructose may be higher than $25 \mathrm{~g}$, and fructose concentration less than $50 \mathrm{~g}$ has low yield. These assumptions are incorrect. Whilst it is possible that patients may consume up to $50 \mathrm{~g}$ fructose/day, this amount is usually not ingested all at once. Because the maximum absorptive capacity for a single dose is $25 \mathrm{~g}$ for healthy subjects, a higher dose will give a higher and false positive diagnosis of fructose malabsoption/ intolerance. This finding may lead to incorrect diagnosis and unnecessary restriction of fructose products in diet, when in fact the subject may have normal fructose absorption capacity. Also performing 2 tests for identifying fructose intolerance seems impractical and should be avoided. Also, we disagree with recommendation that fructose breath test should be performed only for research purposes, ${ }^{3}$ as doing so will deprive patients of an im- portant diagnosis. Also many of them will be falsely labelled as IBS.

It was somewhat surprising that the authors did not reference the only well controlled, dose-response, fructose absorption study in healthy humans. ${ }^{4}$ We believe that the ideal test dose for patients with suspected fructose intolerance is $25 \mathrm{~g}$, and breath samples should be obtained every 30 minutes for 3 hours, and analyzed for $\mathrm{H}_{2}$ and $\mathrm{CH}_{4}$ levels. ${ }^{4}$ This standardized diagnostic approach for fructose breath test should facilitate better characterization of fructose malabsorption in patients with unexplained gas and bloating, and this has been shown to be clinically useful in a large group of 429 consecutive patients.

\section{Askin Erdogan, ${ }^{1}$ Enrique Coss Adame, ${ }^{2}$ Siegfried $\mathrm{Yu}^{1}{ }^{1}$ Kulthep Rattanakovit ${ }^{1}$ and Satish S C Rao ${ }^{1}$ \\ ${ }^{1}$ Section of Gastroenterology and Hepatology, Medical College of Georgia, Georgia Regents University, Augusta, GA, USA; and \\ ${ }^{2}$ Universidad Nacional Autónoma de México, México City, México}

1. Goebel-Stengel M, Stengel A, Schmidtmann M, Voort I, Kobelt P, Monnikes H. Unclear abdominal discomfort: pivotal role of carbohydrate malabsorption. J Neurogastroenterol Motil 2014;20:228-235.

2. Sung HY, Kim YS. Fructose malabsorption in patients with irritable bowel syndrome-like symptoms: what is the role in the pathogenesis and clinical implication? J Neurogastroenterol Motil 2014;20:135-137.

3. Gasbarrini A, Corazza GR, Gasbarrini G, et al. Methodology and indications of H2-breath testing in gastrointestinal diseases: the Rome Consensus Conference. Aliment Pharmacol Ther 2009;29(suppl 1): 1-49.

4. Rao SS, Attaluri A, Anderson L, Stumbo P. Ability of the normal human small intestine to absorb fructose: evaluation by breath testing. Clin Gastroenterol Hepatol 2007;5:959-963.

5. Rao N, Coss-Adame E, Badger C, Rao SS. How useful are breath tests in the diagnosis of SIBO or carbohydrate intolerance. Am J Gastroenterol 2012;107:S134.

Conflicts of interest: None. 